\title{
Association of COL9A3 trp3 polymorphism with intervertebral disk degeneration: a meta-analysis
}

\author{
Donghua Huang ${ }^{\dagger}, X$ iangyu Deng ${ }^{\dagger}$, Kaige Ma, Fashuai Wu, Deyao Shi, Hang Liang, Sheng Chen and Zengwu Shao*
}

\begin{abstract}
Background: Intervertebral disk degeneration (IDD) is a common musculoskeletal disease associated with genetic factors. COL9A3 gene encodes the a3 (IX) chain of type IX collagen that is part of the interior structure of the disc. Mutations in COL9A3 gene sequence, leading to an Arg103Trp substitution in its 3 chain (the Trp3 allele at rs61734651 site), respectively, have been found to be connected with IDD occurrence in several studies. However, those studies have showed conflict results. Thus, a meta-analysis has been performed to assess the associations between the COL9A3 trp3 polymorphism and IDD.

Methods: Data were gathered from the following four electronic databases: PubMed, Web of Science (WOS), Embase and Cochrane library up to January 01, 2018. The pooled odds ratio (polled ORs) and 95\% confidence interval (Cl) were calculated to evaluate the strength of relationship between the COL9A3 trp3 polymorphism and IDD.

Results: Eleven eligible studies with 1631 cases of IDD and 1366 controls were included in this meta-analysis. The results indicated that the COL9A3 trp3 polymorphism was not associated with IDD (trp3 positive versus trp3 negative: $\mathrm{OR}=1.31,95 \% \mathrm{Cl}=0.78-2.21, P=0.309)$. Furthermore, the Egger's test and the Begg funnel plot did not show any evidence of publication bias.

Conclusions: Our results suggest that the COL9A3 trp3 polymorphism might not be associated with IDD. Nor did we find any relationship in subgroup analyses stratified by gender and ethnicity. Future researches with larger samples are required to verify this outcome.
\end{abstract}

Keywords: COL9A3, Single nucleotide polymorphism, trp3, Intervertebral disk degeneration, Meta-analysis

\section{Background}

Low back pain (LBP), a common musculoskeletal disorder, involves the muscle, nerve, and bone tissues of back [1-3]. It has been reported that LBP ranked first in terms of disability and sixth in terms of total burden as part of the Global Burden of Disease 2010 Study [4]. Intervertebral disk degeneration (IDD), describing the natural destruction of intervertebral disk inside the spine, has been considered as one of the major causes to motor losses and LBP. The etiology and pathogenesis of IDD is so complicated that IDD is thought to be the results of co-effects of ageing and relevant environmental

\footnotetext{
* Correspondence: szwpro@163.com

${ }^{\dagger}$ Donghua Huang and Xiangyu Deng contributed equally to this work. Department of Orthopaedics, Union Hospital, Tongji Medical College, Huazhong University of Science and Technology, Wuhan 430022, China
}

factors such as sporting activities, damage, occupation, and smoking [5-9]. However, there have been many articles establishing a close relationship between heredity and IDD recently [10-12].

For the last several years, many genes have been discovered to be associated with IDD, some of which are collagen genes, such as Collagen I, IX and XI genes [12-14]. Among these genes, the association of collagen type IX alpha 3 chain (COL9A3) gene polymorphism with IDD risk has been studied much frequently. COL9A3 gene, located in the chromosome 20q13.3, encodes the $\alpha 3$ (IX) chain of type IX collagen which is part of the interior structure of the disc, nucleus pulposus [14-16]. Mutations in COL9A3 gene leading to an Arg103Trp substitution in its 3 chain (the Trp3 allele at rs61734651 site), in other words, this change in collagen IX by substitution of

(c) The Author(s). 2018 Open Access This article is distributed under the terms of the Creative Commons Attribution 4.0 International License (http://creativecommons.org/licenses/by/4.0/) which permits unrestricted use, distribution, and reproduction in any medium, provided you give appropriate credit to the original author(s) and the source, provide a link to the Creative Commons license, and indicate if changes were made. The Creative Commons Public Domain Dedication waiver (http://creativecommons.org/publicdomain/zero/1.0/) applies to the data made available in this article, unless otherwise stated. 
glutamine by tryptophan, which is relative rare in collagen, can contribute to a disorder in the collagen properties of intervertebral disc. The increasing proportion of tryptophan in collagen can result in alterations in collagen triple helix, as well as interfering the interaction between collagens IX and II or disturbing the process of lysyl oxidase, which catalyzes cross-link formation, finally leading to disc disease [17-20].

However, recent studies have obtained conflicting results. Some of them, such as Toktas et al. [11] and Paassita et al. [17], found that trp3 gene was a risk fact of IDD or the spinal stenosis with spondylolisthesis which is one type of IDD. Others, such as Eskola et al. [21] and Rathod et al. [22], did not observe a relationship between trp3 and IDD. Besides, Bagheri et al. [18], only got an association of trp3 with IDD in males. A few articles reported the association of trp3 with ethnicity [23]. But no meta-analysis has investigated the association between IDD and COL9A3 trp3 polymorphism up to now. Therefore, we performed a meta-analysis to evaluate the connection between them. In this study, we aim to identify the association of genetic mutations with IDD, which is likely to be of significant importance and might help identify 'high-risk' individuals of IDD or guide the clinical treatment of some specific individuals.

\section{Methods}

\section{Strategy for literature search}

In order to identify all articles that studied the association of COL9A3 Trp3 polymorphism with IDD, we searched electronic databases including PubMed, Web of Science (WOS), Embase and Cochrane library up to January 01, 2018. The search strategy to screen out all possible articles involved the use of the following terms: ("COL9A3" OR "Collagen 9 alpha-3") AND ("Gene polymorphism") AND ("Intervertebral Disk Degeneration" OR “Disk Degeneration, Intervertebral" OR "IDD” OR "Disc Degeneration" OR "disc herniation" OR "low back pain"); (“Trp3” OR "rs61734651” OR “20q13.33” OR "arg103") AND ("Gene polymorphism") AND ("Intervertebral Disk Degeneration" OR "Disk Degeneration, Intervertebral" OR "IDD” OR "Disc Degeneration" OR “disc herniation" OR "low back pain"); ("COL9A3" OR "Collagen 9 alpha-3") AND (“Trp3” OR "rs61734651" OR "20q13.33" OR "arg103") AND ("Intervertebral Disk Degeneration" OR "Disk Degeneration, Intervertebral" OR "IDD" OR "Disc Degeneration" OR "disc herniation" OR "low back pain"). In order to increase the sensitivity of the searching strategy, both MeSH terms and free words were applied.

\section{Inclusion and exclusion criteria}

Studies included in this meta-analysis should satisfy the following inclusion criteria: (1) Evaluation of the association between COL9A3 trp3 polymorphism and the risk of IDD; (2) Human subjects; (3) Case-control study; and (4) Available genotype data were provided to calculate the odds ratios (ORs) and 95\% confidence interval (CI).

Correspondingly, the exclusion criteria were defined as: (1) Comments, reviews or animal studies; (2) Duplicate reports with previous publications; (3) the study only described data of case population; (4) Studies without available genotype frequencies.

All retrieved articles were evaluated and discussed to achieve accordance by two junior investigators depending on the inclusion and exclusion strategies independently. If a conflict (among the basic information, data, and the quality of articles separately extracted by two investigators) still existed, a senior author was invited to extract the specific data independently using blind method. Then comparing the results with the two junior investigators to solve the problem and finally come to a consistency.

\section{Data extraction}

The following characteristics of each study were collected: (1) name of the first author; (2) year of publication; (3) country of enrollment; (4) ethnicity of the study population; (5) age and gender of individuals included; (6) diagnostic criteria for IDD cases; (7) genotyping methods; (8) source of controls; (9) matching items; (10) number of subjects under IDD cases and controls; (11) Relation with IDD; Data were extracted carefully from all eligible publications independently by two investigators. For conflict resolution, an agreement was reached by discussion.

\section{Methodological quality assessment}

The two investigators assessed the qualities of all the included studies separately using the Clark scores system, which contains 10 items [24, 25]. Scores below 5 indicate low quality, while 5-7 scores represent moderate quality and 8-10 scores denote high quality $[24,25]$.

\section{Statistical analysis}

The PRISMA checklists and their guidelines were cautiously followed during the whole process of the study [26]. The association strength between COL9A3 trp3 polymorphism and IDD risk was assessed by combining ORs with $95 \% \mathrm{CI}$. The estimations of pooled ORs were determined by the weighted average OR from each study. Significance was identified by a $P$-value less than 0.05 in Z-test. The pooled ORs and $95 \% \mathrm{CI}$ were calculated for trp3 positive (the mutation type) versus trp3 negative (the wild type). Because seven studies [11, 14, $18,23,27-29]$ included in this meta-analysis only exhibited data in "Trp3 positive versus Trp3 negative" form. In other words, these studies did not have enough data 
to calculate ORs and $95 \% \mathrm{CI}$ for five comparison models. In addition, although the other four studies $[17,21,22,30]$ included this meta-analysis showed separate data in homozygous type (TGG/TGG), heterozygous type (TGG/CGG) and wild type (the others which not include TGG at this site, such as CGG/CGG) for trp3, the number of subjects for homozygous type (TGG/TGG) was too small with no more than two subjects observed in each study. So we combined homozygous and heterozygous type together as trp3 positive (TGG/TGG, TGG/CGG) and the wild type was defined as trp3 negative (the others which not include TGG at this site). In other words, the trp3 positive was defined as the presence of at least 1 Trp3 allele and the trp3 negative were the types without Trp3 allele. The statistical heterogeneity was verified by $I^{2}$ statistics. Fixed-effect model was used to estimate the ORs and $95 \% \mathrm{CI}$ when heterogeneity was low $\left(I^{2}<50 \%\right)$, while the random effects was adopted when heterogeneity was high $\left(I^{2}>50 \%\right)$ [31]. Sensitivity analyses were also performed to evaluate the function of an individual study on the pooled ORs by removing each study in turn. All analyses were performed using STATA 14
(Stata, College Station, TX). Subgroup analyses were performed to find whether sex or ethnicity of studies was linked to the value of the pooled ORs and $95 \% \mathrm{CI}$ as well. Because only few studies included separate data of degree of IDD, we do not conduct a subgroup analysis stratified by disease degree. All $P$-values were two-sided. Publication bias was checked using the Begg funnel plot [32] and the Egger's test [33] $(P<0.05$ was considered statistically significant).

\section{Results}

\section{Characteristics of the studies}

A flow chart, presented as Fig. 1, describes the exclusion/inclusion of publications. The comprehensive articles search screened out 381 potentially relevant articles, of which 82 articles were excluded for duplication and 281 articles were removed because of obvious irrelevance after browsing the title and/or abstract. Two articles were excluded because they did not study trp3, COL9A3 or IDD; one article was removed because it is a duplicate report; three articles were excluded because they did not have detailed data; another article was

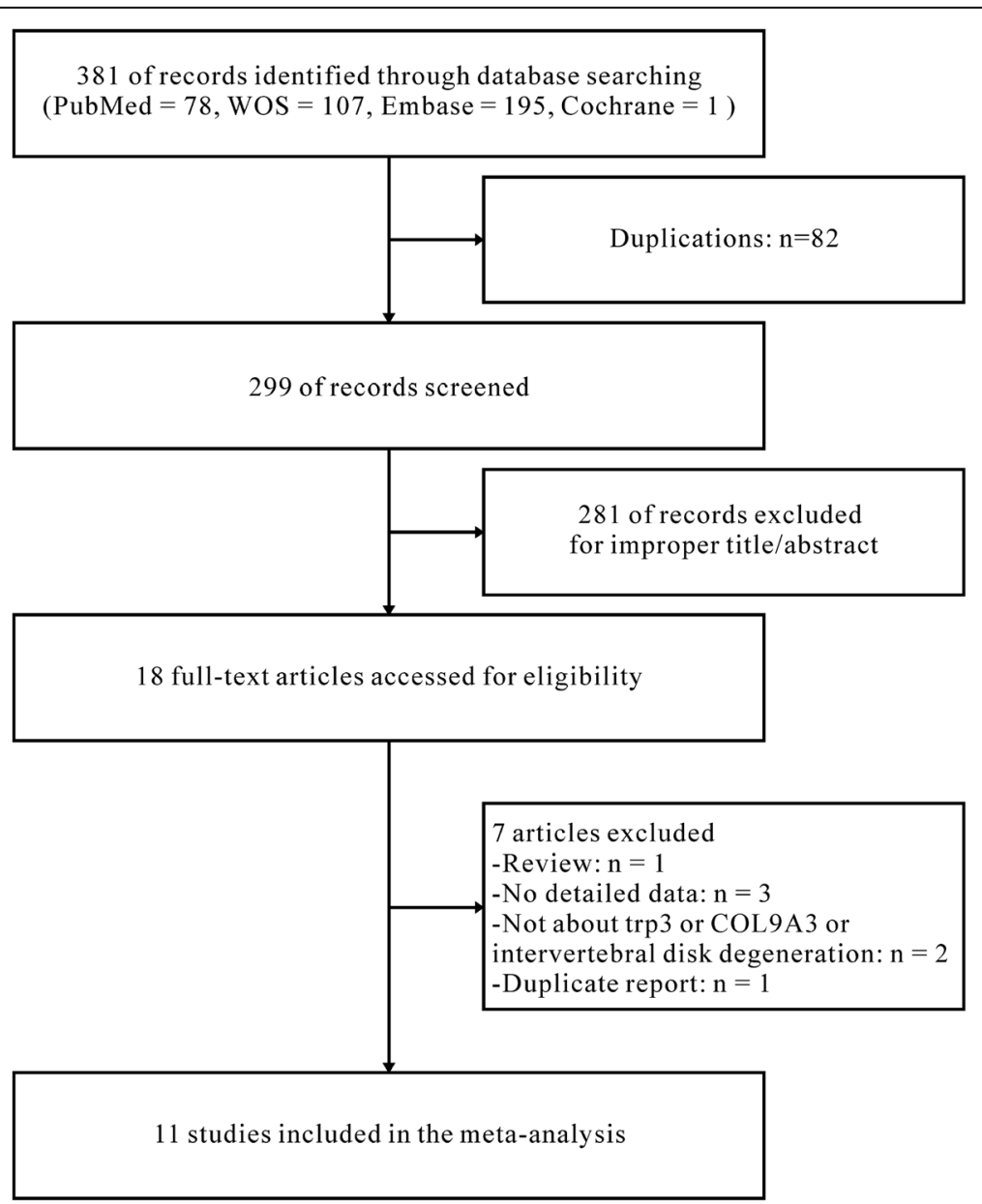

Fig. 1 Flow diagram for the selection of studies 
removed because it was a review. Finally, 11 case-control studies $[11,14,17,18,21-23,27-30]$ were identified due to the inclusion criteria.

As shown in Tables 1, 11 eligible studies for COL9A3 trp3 with 1631 cases of IDD and 1366 controls were included in this meta-analysis. The characteristics of all the included studies are also listed in the Tables 1 and 2, including the year, country and continent of studies, the ethnicity, age and gender of subjects, the diagnosis methods, genotyping methods, source of controls, matching items of cases and controls, relation with IDD and the number of subjects in control/case group in each studies. The quality assessment of study was listed in Table 3.

However, Jim et al. [23] measured the 804 subjects with no Trp3 positive subjects neither in case nor in control groups.(Table 2) This proportion is largely deviated from other studies included. We speculate that it might be something wrong in its genotyping method or there might be a selection bias in its subjects. So Jim et al. [23] is excluded in the following analyses.

\section{Association between COL9A3 trp3 polymorphism and IDD risk in overall}

Significant heterogeneity was found among the studies of trp3 in the overall meta-analysis. So the random effects model was applied to evaluate the connection between trp3 polymorphism and IDD risk. The result of the evaluation showed that there was no association of trp3 polymorphism with IDD risk (as shown in Fig. 2a and Table 4 , trp3 positive versus trp3 negative: ORs = $1.31,95 \% \mathrm{CI}=0.78-2.21, P=0.309$; heterogeneity test $\left.X^{2}=25.31, P<0.10, I^{2}=64.40 \%\right)$.

\section{Subgroup analysis between COL9A3 trp3 polymorphism and IDD risk based on gender}

Subgroup meta-analysis of the studies based on gender (male and female) showed no significant heterogeneity. Thus, the fixed effects model was used to assess the relationship between trp3 polymorphism and IDD risk. The result of the evaluation indicated that trp3 polymorphism was not associated with IDD risk in both gender (as shown in Fig. 2b and Table 4, for male subgroup, trp3 positive versus trp3 negative: $\mathrm{ORs}=1.30,95 \% \mathrm{CI}=0.77-$ 2.17, $P=0.322$; heterogeneity test $X^{2}=11.30, P<0.10, I^{2}$ $=46.90 \%$; for female subgroup, trp3 positive versus trp3 negative: $\mathrm{ORs}=1.11,95 \% \mathrm{CI}=0.62-2.01, P=0.725$; heterogeneity test $\left.X^{2}=1,64, P>0.10, I^{2}=0.00 \%\right)$.

\section{Subgroup analysis between COL9A3 trp3 polymorphism and IDD risk based on ethnicity}

Subgroup analysis was conducted according to different ethnicity (Asian, Caucasian and unclear) and was observed significant heterogeneity. So the random effects model was used to test the association between trp3 polymorphism and IDD risk. The result of the calculations indicated that trp3 polymorphism had no associations to IDD risk in any ethnicity (as shown in Fig. $2 \mathrm{c}$ and Table 4, for Asian subgroup, trp3 positive versus trp3 negative: ORs $=1.22$, $95 \% \mathrm{CI}=0.52-2.89, P=0.645$; heterogeneity test $\chi^{2}=1.53$, $P>0.10, I^{2}=34.70 \%$. for Caucasian subgroup, trp3 positive versus trp3 negative: $\mathrm{ORs}=1.53,95 \% \mathrm{CI}=0.55-4.29, P=$ 0.417 ; heterogeneity test $\chi^{2}=10.17, P<0.10, I^{2}=80.30 \%$; for unclear subgroup, trp3 positive versus trp3 negative: ORs $=0.96,95 \% \mathrm{CI}=0.53-1.75, \quad P=0.907$; heterogeneity test $\left.X^{2}=4.96, P>0.10, I^{2}=19.3 \%\right)$.

\section{Sensitivity analysis}

Sensitivity analysis was conducted to evaluate the influence set by the individual study on the pooled ORs for COL9A3 trp3 polymorphism by deleting one study each turn in every genetic model (as shown in Fig. 3). There was no change in the significance of any outcomes, indicating the stability of the results in this meta-analysis.

\section{Publication Bias}

The Begg funnel plot (as shown in Fig. 4) and the Egger's test were performed to assess publication bias in the selected literature. No evidence of publication bias was observed in this study (Begg's test: $P=0.283$, Egger's test: $t=$ $0.54,95 \% \mathrm{CI}=-2.88-4.64, P=0.606$ for $C O L 9 A 3 \operatorname{trp} 3)$.

\section{Discussion}

IDD, a common musculoskeletal disease, is widely considered as multifactorial diseases enforcing economic and medical burdens to society. Genetic factors have been considered as one of the leading causes of IDD [7, 11, 34]. $C O L 9 A 3$, an extracellular matrix molecule present in the nucleus pulposus of the intervertebral disc and cartilage, codes for Collagen IX [35]. Collagen IX is vital for the normal cartilage development or maintenance. Mutations in COL9A3 could cause chondrodysplasias in humans as well as articular cartilage and intervertebral discs degeneration in mice [36]. COL9A3 gene was observed to be a key genetic influencer in the process of IDD [23]. Previous studies have reported the association between the COL9A3 trp3 polymorphism and IDD, but with conflicting results. With the studies with larger sample sizes of predisposing gene polymorphism, it would be much more reliable to discover the connection between candidate genes and specific type of diseases. In order to solve the inconsistence, meta-analysis was performed to examine the association of COL9A3 trp3 polymorphism with IDD risk by critically reviewing 11 studies. Its strength came from the accumulation of various published data, offering more information to explore significant differences.

The pooled ORs (trp3 positive versus trp3 negative) and $95 \% \mathrm{CI}$ did not show a significant association of 


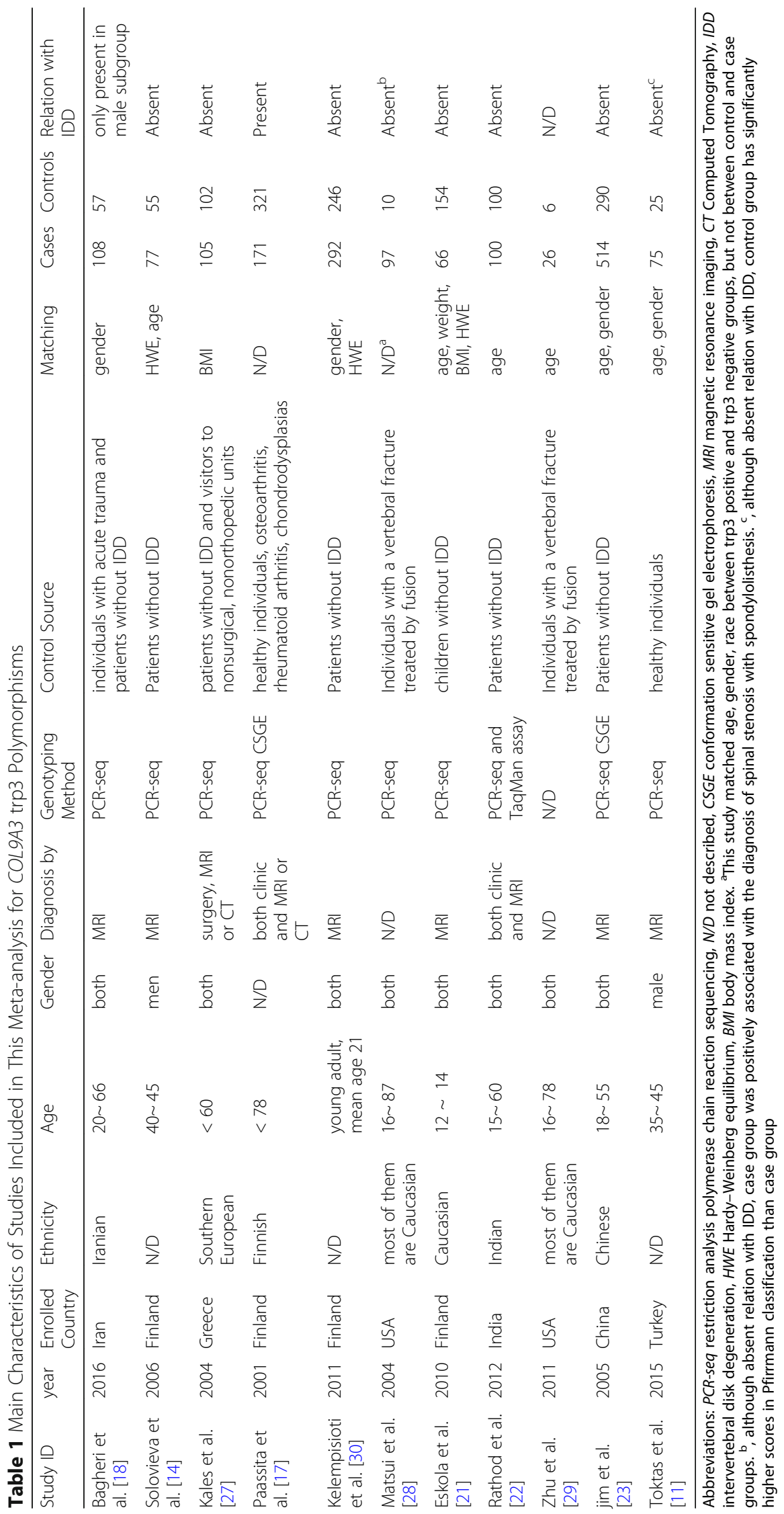


Table 2 Distribution of Genotypes and COL9A3 trp3 Polymorphisms Among Cases and Controls

\begin{tabular}{|c|c|c|c|c|c|c|c|}
\hline \multirow[t]{2}{*}{ Study ID } & \multirow[t]{2}{*}{ Year } & \multirow[t]{2}{*}{ Continent } & \multirow[t]{2}{*}{ Gender } & \multicolumn{2}{|l|}{ Case } & \multicolumn{2}{|l|}{ Control } \\
\hline & & & & Trp3 positive & Trp3 negative & Trp3 positive & Trp3 negative \\
\hline \multirow[t]{3}{*}{ Bagheri et al. [18] } & \multirow[t]{3}{*}{2016} & \multirow[t]{3}{*}{ Asia } & male & 12 & 21 & 2 & 21 \\
\hline & & & female & 17 & 58 & 8 & 26 \\
\hline & & & overall & 29 & 79 & 10 & 47 \\
\hline Solovieva et al. [14] & 2006 & Europe & male & 15 & 62 & 8 & 47 \\
\hline \multirow[t]{3}{*}{ Kales et al. [27] } & \multirow[t]{3}{*}{2004} & \multirow[t]{3}{*}{ Europe } & male & 6 & 62 & 1 & 46 \\
\hline & & & female & 3 & 34 & 4 & 51 \\
\hline & & & overall & 9 & 96 & 5 & 97 \\
\hline Paassita et al. [17] & 2001 & Europe & unknown & 40 & 131 & 30 & 291 \\
\hline Kelempisioti et al. [30] & 2011 & Europe & overall & 43 & 249 & 52 & 194 \\
\hline Matsui et al. [28] & 2004 & America & overall & 7 & 90 & 0 & 10 \\
\hline \multirow[t]{3}{*}{ Eskola et al. [21] } & \multirow[t]{3}{*}{2010} & \multirow[t]{3}{*}{ Europe } & male & 2 & 28 & 14 & 59 \\
\hline & & & female & 7 & 29 & 17 & 64 \\
\hline & & & overall & 9 & 57 & 31 & 123 \\
\hline \multirow[t]{3}{*}{ Rathod et al. [22] } & \multirow[t]{3}{*}{2012} & \multirow[t]{3}{*}{ Asia } & male & 3 & 62 & 7 & 60 \\
\hline & & & female & 2 & 33 & 0 & 33 \\
\hline & & & overall & 5 & 95 & 7 & 93 \\
\hline \multirow[t]{3}{*}{ Zhu et al. [29] } & \multirow[t]{3}{*}{2011} & \multirow[t]{3}{*}{ America } & male & 3 & 11 & 0 & 2 \\
\hline & & & female & 3 & 9 & 0 & 4 \\
\hline & & & overall & 6 & 20 & 0 & 6 \\
\hline Jim et al. [23] & 2005 & Asia & overall & 0 & 290 & 0 & 514 \\
\hline Toktas et al. [11] & 2015 & Europe & male & 5 & 70 & 0 & 25 \\
\hline
\end{tabular}

COL9A3 trp3 polymorphism with IDD risk in the overall populations. Different COL9A3 trp3 frequencies have been reported in two genders of subjects (male and female) [18]. So we performed a stratified analysis by gender to determine whether there was an association between trp3 and IDD differed by gender. We also found

Table 3 Quality Assessment of the Included Articles

\begin{tabular}{|c|c|c|c|c|c|c|c|c|c|c|c|c|}
\hline Author & Year & A & $B$ & C & $\mathrm{D}$ & $E$ & $\mathrm{~F}$ & G & $\mathrm{H}$ & 1 & $J$ & Sum \\
\hline Bagheri et al. [18] & 2016 & 1 & 0 & 1 & 1 & 1 & 0 & 0 & 1 & 1 & 0 & 6 \\
\hline Solovieva et al. [14] & 2006 & 1 & 1 & 1 & 1 & 1 & 0 & 0 & 1 & 1 & 0 & 7 \\
\hline Kales et al. [27] & 2004 & 1 & 0 & 1 & 1 & 1 & 0 & 0 & 1 & 1 & 0 & 6 \\
\hline Paassita et al. [17] & 2001 & 1 & 0 & 1 & 1 & 1 & 0 & 0 & 1 & 0 & 0 & 5 \\
\hline Kelempisioti et al. [30] & 2011 & 0 & 1 & 1 & 1 & 1 & 0 & 0 & 1 & 1 & 0 & 6 \\
\hline Matsui et al. [28] & 2004 & 0 & 0 & 1 & 1 & 1 & 1 & 0 & 1 & 0 & 0 & 5 \\
\hline Eskola et al. [21] & 2010 & 1 & 1 & 1 & 1 & 1 & 0 & 0 & 1 & 1 & 0 & 7 \\
\hline Rathod et al. [22] & 2012 & 1 & 0 & 1 & 1 & 1 & 0 & 0 & 1 & 1 & 0 & 6 \\
\hline Zhu et al. [29] & 2011 & 0 & 0 & 1 & 1 & 1 & 0 & 0 & 1 & 1 & 0 & 5 \\
\hline Jim et al. [23] & 2005 & 1 & 0 & 1 & 1 & 1 & 0 & 0 & 1 & 1 & 0 & 6 \\
\hline Toktas et al. [11] & 2015 & 0 & 0 & 1 & 1 & 1 & 0 & 0 & 1 & 1 & 0 & 5 \\
\hline
\end{tabular}

no association of COL9A3 trp3 polymorphism with IDD risk both in male or female subgroup. To our limited knowledge, ethnicity may contribute to different genetic characteristics of IDD. Hence, we also performed a subgroup analysis by ethnicity and the outcomes indicated no association of COL9A3 trp3 polymorphism with IDD risk in any of ethnicity subgroup. Based on the analyses above, we speculated that COL9A3 trp3 might be a minor factor in genetic etiology of IDD risk due to the small amount of COL9A3 inside the intervertebral discs [37]. All of the results above do not eliminate the possibility of a clinically vital association that remains to be explored more carefully in convincing studies of larger sample sizes.

No significant heterogeneity was observed in subgroup analysis of gender, whereas there existed heterogeneities in the overall comparisons and subgroup analysis of continent for trp3 and IDD risk. To search the source of heterogeneity, we observed that $I^{2}$ values had significantly decreased after excluding Paassita et al. [17] or Kelempisioti et al. [30] in overall analysis. We also found that $I^{2}$ values had significantly decreased after excluding a study of Paassita et al. [17] in subgroup analysis of Europe continent. The results indicated that the major source of the heterogeneity might result from these 


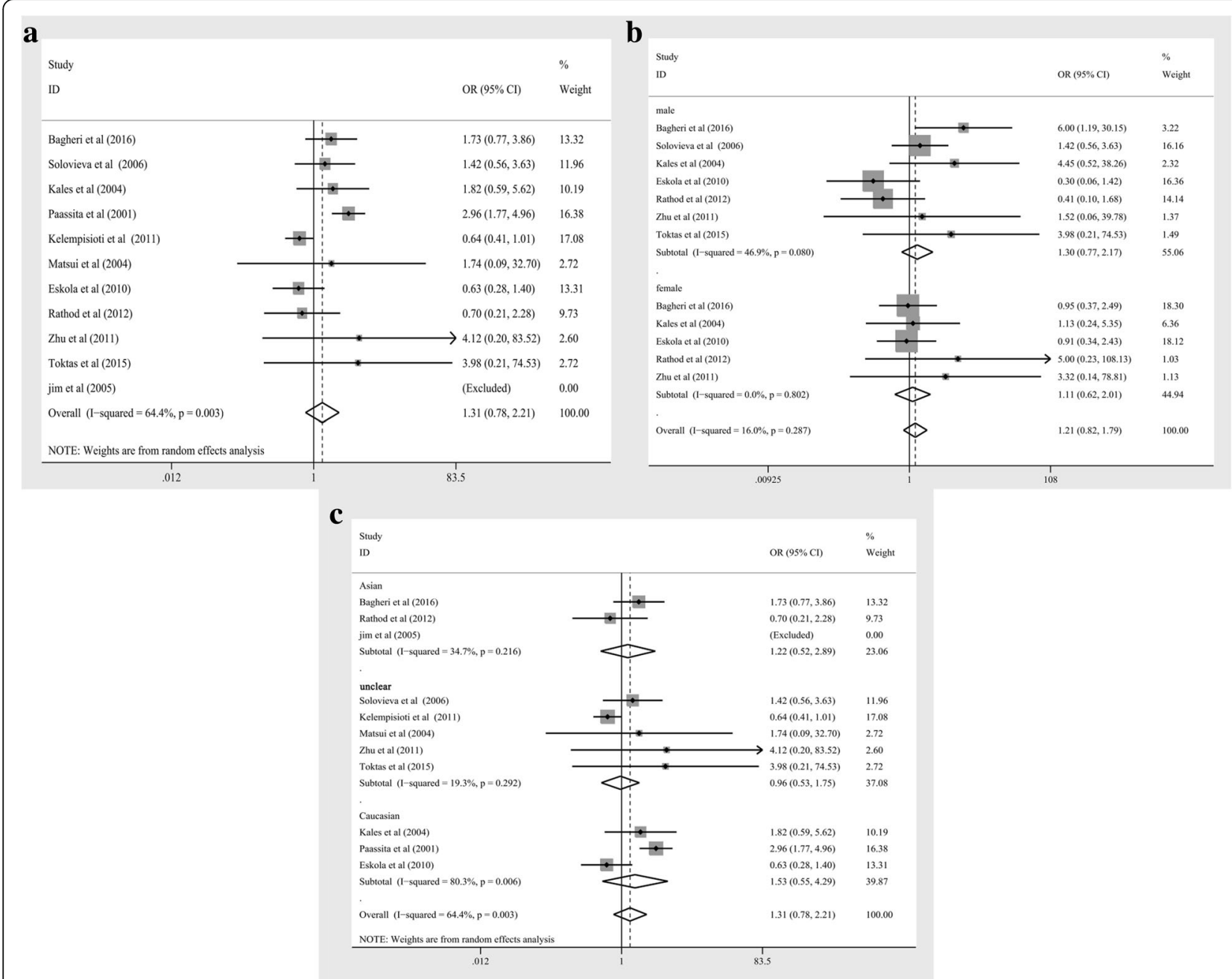

Fig. 2 Forest plot of the association between COL9A3 trp3 polymorphisms and IDD (trp3 positive versus trp3 negative) for: (a) overall analysis and subgroup analyses stratified by (b) gender, (c) ethnicity

Table 4 Statistics of polled ORs and Heterogeneity for Overall and Sub Group Analyses of COL9A3 trp3 Polymorphism

\begin{tabular}{|c|c|c|c|c|c|c|c|c|}
\hline \multirow[t]{2}{*}{ COL9A3 trp3 } & & \multirow[t]{2}{*}{$N$} & \multicolumn{2}{|l|}{ ORs analyses } & \multicolumn{3}{|c|}{ Heterogeneity Analyses } & \multirow{2}{*}{$\begin{array}{l}\text { Model } \\
\text { Used } \\
\text { for } \\
\text { Meta- } \\
\text { analysis }\end{array}$} \\
\hline & & & polled ORs (95\% Cl) & $P$ value & $\overline{x^{2}}$ & $P_{\text {heterogeneity }}$ & $\mathrm{I}^{2}(\%)$ & \\
\hline Overall & & 11 & $1.31(0.78,2.21)$ & 0.309 & 25.31 & 0.003 & $64.40 \%$ & Random \\
\hline \multirow[t]{2}{*}{ sub group analysis by gender } & male & 7 & $1.30(0.77,2.17)$ & 0.322 & 11.30 & 0.080 & $46.90 \%$ & Fixed \\
\hline & female & 5 & $1.11(0.62,2.01)$ & 0.725 & 1.64 & 0.802 & $0.00 \%$ & \\
\hline \multirow[t]{3}{*}{ sub group analysis by ethnicity } & Asian & 3 & $1.22(0.52,2.89)$ & 0.645 & 1.53 & 0.216 & $34.70 \%$ & Random \\
\hline & Caucasian & 3 & $1.53(0.55,4.29)$ & 0.417 & 10.17 & 0.006 & $80.3 \%$ & \\
\hline & unclear & 5 & $0.96(0.53,1.75)$ & 0.907 & 4.96 & 0.292 & $19.3 \%$ & \\
\hline
\end{tabular}




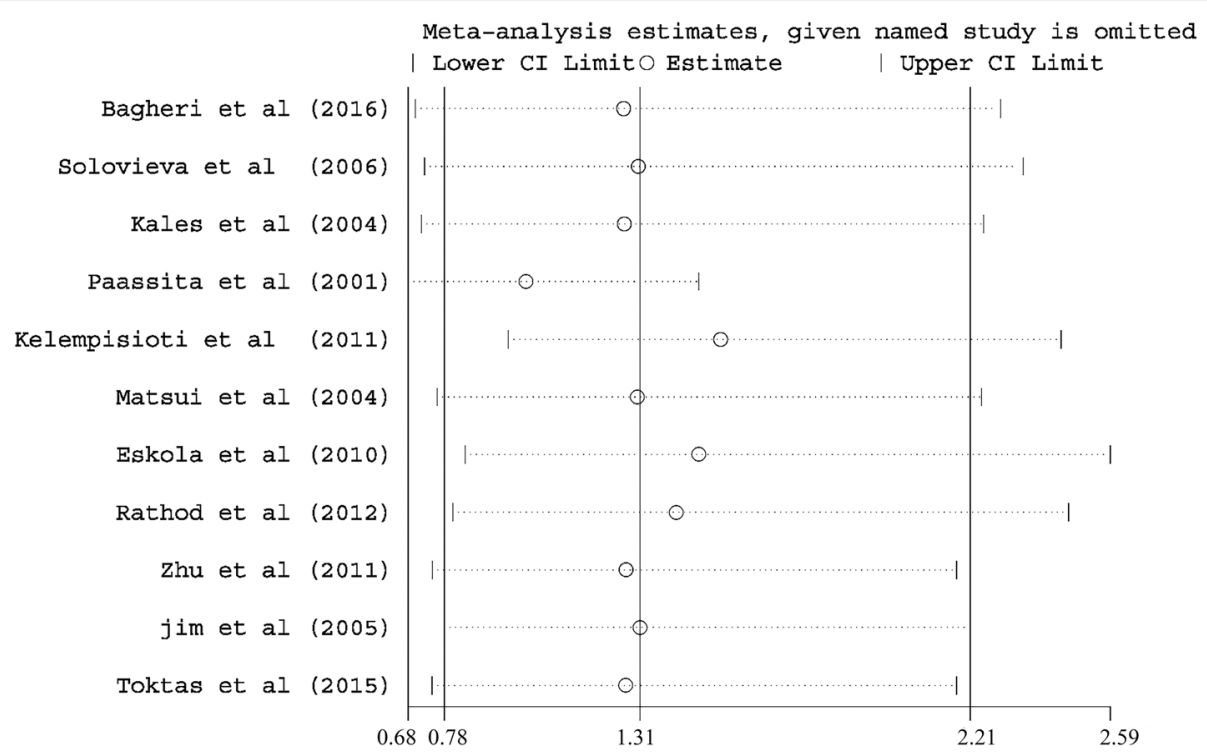

Fig. 3 Sensitivity analysis for confirmation of the stability of the pooled results

studies. However, heterogeneity did not seem to influence the results, because the lack of association between trp3 and IDD was not altered after excluding either of study mentioned above.

Moreover, no significant change of results was identified by sensitivity analyses, which indicating the reliability of results. These suggested the reliability of the results. Publication bias was also tested in this study. On the basis that a meta-analysis collects various data from numerous studies, the effect of publication bias among the articles included in the study can influence the meta-analytic results. Neither the Egger's test nor the Begg funnel plot showed significant publication bias for this analysis. Although the results are reliable, more studies are required to be conducted in order to confirm the outcome of this meta-analysis.

Our meta-analysis has several strengths. Firstly, to our best knowledge, this is the first meta-analysis focusing on the connection between COL9A3 trp3 polymorphism and the risk of IDD. We suggest that such a method of incorporating the outcomes of related studies may help us to understand the effect of polymorphism on disease development better. Secondly, we also have taken the gender and ethnicity of subjects into account. This study included researches of Asia (Iran, China and India), Europe (Finland, Greece and Turkey) and America (USA), containing different kinds of ethnicities and enrolling both male and female. So the results are much more

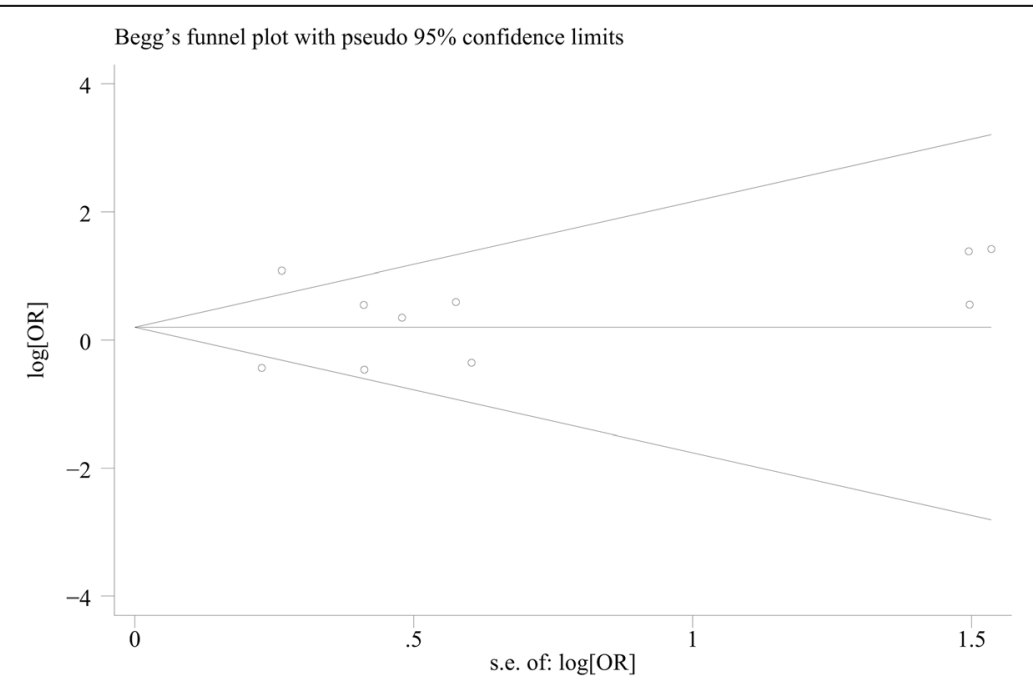

Fig. 4 Begg funnel plot for the identification of potential missing studies 
comprehensive. Moreover, several strategies and strict principle were applied to evaluate the methodological quality of the studies and most of the studies included in this meta-analysis possessed moderate or high qualities.

The present meta-analysis also has a few limitations that should be taken into account. Firstly, the number of filtered studies for COL9A3 trp3 polymorphism is a little bit small. Secondly, the heterogeneity was a little bit high when overall and sub group of ethnicity analyses were conducted, contributing to a cautious acceptance of the results. What's more, some studies were removed from our research for lacking detailed data, which may contribute to selection bias. Limited to data, we only analyze trp3 positive versus trp3 negative to estimate the ORs and $95 \% \mathrm{CI}$ rather than five models (allele, homozygote, recessive, dominant and heterozygote models). This may also influence the reliability of outcomes. Finally, although most of articles in this meta-analysis made a good match of age, gender or other items which might influence the results, some articles did not take certain items into account or even did not mention the match points. These confounding factors might affect the results.

\section{Conclusions}

Basing on the epidemiological evidence, our meta-analysis suggested that COL9A3 trp3 polymorphism did not seem to be connected to risk of IDD in any gender, continent or ethnicity of people. Future researches with larger sample sizes are required to verify this outcome.

\section{Abbreviations \\ Cl: Confidence interval; COL9A3: Collagen type IX alpha 3 chain; IDD: Intervertebral disk degeneration; LBP: Low back pain; ORs: Odds ratios; WOS: Web of Science}

\section{Acknowledgments}

We would like to thank all the people who helped us in the current study.

\section{Funding}

This study was supported by the National Key Research and Development Program of China (2016YFC1100100) and the Major Research Plan of National Natural Science Foundation of China (No.91649204).

\section{Availability of data and materials}

All data generated or analyzed during this study are included in this published article and its supplementary information files.

\footnotetext{
Authors' contributions

$\mathrm{DH}$ contributed to the idea of this study. DH, XD and HL searched literatures and screened them independently. Any disagreement was solved by consulting the senior authors (ZS and KM). XD, DS and HL screened data from the eleven final articles and make Tables. DH, FW and SC played an important role in analyzing the outcomes. $\mathrm{XD}$ and $\mathrm{DH}$ conducted the data analyses and make graphs. XD and SC wrote the first draft. DS and FW revised the manuscript. $\mathrm{ZS}$ and $\mathrm{KM}$ polished the draft. $\mathrm{ZS}$ approved the final version.
}

Ethics approval and consent to participate

Not applicable
Consent for publication

Not applicable

\section{Competing interests}

The authors declare that they have no competing interests.

\section{Publisher's Note}

Springer Nature remains neutral with regard to jurisdictional claims in published maps and institutional affiliations.

Received: 30 January 2018 Accepted: 4 October 2018

Published online: 20 October 2018

\section{References}

1. Mehrdad RMM, Shams-Hosseini NSM, Aghdaei SM, Yousefian MM. Prevalence of low Back pain in health care workers and comparison with other occupational categories in Iran: a systematic review. Iran J Med Sci. 2016;41(6):467-78

2. Zhang YG, Guo TM, Guo X, Wu SX. Clinical diagnosis for discogenic low back pain. Int J Biol Sci. 2009;5(7):647-58.

3. Zhang $Y H$, Zhao CQ, Jiang LS, Chen XD, Dai LY. Modic changes: a systematic review of the literature. Eur Spine J. 2008;17(10):1289-99.

4. Hoy D, March L, Brooks P, Blyth F, Woolf A, Bain C, Williams G, Smith E, Vos $\mathrm{T}$, Barendregt J, et al. The global burden of low back pain: estimates from the global burden of disease 2010 study. Ann Rheum Dis. 2014;73(6):96874.

5. Cheung KM, Samartzis D, Karppinen J, Mok FP, Ho DW, Fong DY, Luk KD. Intervertebral disc degeneration: new insights based on "skipped" level disc pathology. Arthritis Rheum. 2010;62(8):2392-400.

6. Rivinoja AE, Paananen MV, Taimela SP, Solovieva S, Okuloff A, Zitting P, Jarvelin MR, Leino-Arjas P, Karppinen Jl. Sports, smoking, and overweight during adolescence as predictors of sciatica in adulthood: a 28-year followup study of a birth cohort. Am J Epidemiol. 2011;173(8):890-7.

7. Battie MC, Videman T. Lumbar disc degeneration: epidemiology and genetics. J Bone Joint Surg Am. 2006;88(Suppl 2):3-9.

8. Videman T, Sarna S, Battie MC, Koskinen S, Gill K, Paananen H, Gibbons L. The long-term effects of physical loading and exercise lifestyles on backrelated symptoms, disability, and spinal pathology among men. Spine. 1995; 20(6):699-709.

9. Heliovaara M. Risk factors for low back pain and sciatica. Ann Med. 1989; 21(4):257-64.

10. Battie MC, Videman T, Gibbons LE, Fisher LD, Manninen H, Gill K. 1995 Volvo award in clinical sciences. Determinants of lumbar disc degeneration. A study relating lifetime exposures and magnetic resonance imaging findings in identical twins. Spine. 1995;20(24):2601-12.

11. Toktas ZO, Eksi MS, Yilmaz B, Demir MK, Ozgen S, Kilic T, Konya D. Association of collagen I, IX and vitamin D receptor gene polymorphisms with radiological severity of intervertebral disc degeneration in southern European ancestor. Eur Spine J. 2015;24(11):2432-41.

12. Valdes AM, Hassett G, Hart DJ, Spector TD. Radiographic progression of lumbar spine disc degeneration is influenced by variation at inflammatory genes: a candidate SNP association study in the Chingford cohort. Spine. 2005;30(21):2445-51

13. Wrocklage C, Wassmann H, Paulus W. COL9A2 allelotypes in intervertebral disc disease. Biochem Biophys Res Commun. 2000;279(2):398-400.

14. Solovieva S, Lohiniva J, Leino-Arjas P, Raininko R, Luoma K, Ala-Kokko L, Riihimaki $\mathrm{H}$. Intervertebral disc degeneration in relation to the COL9A3 and the IL-1ss gene polymorphisms. Eur Spine J. 2006;15(5):613-9.

15. Urban JP, Roberts S. Degeneration of the intervertebral disc. Arthritis Res Ther. 2003;5(3):120-30.

16. Higashino K, Matsui Y, Yagi S, Takata Y, Goto T, Sakai T, Katoh S, Yasui N. The alpha2 type IX collagen tryptophan polymorphism is associated with the severity of disc degeneration in younger patients with herniated nucleus pulposus of the lumbar spine. Int Orthop. 2007;31(1):107-11.

17. Paassilta P, Lohiniva J, Goring HH, Perala M, Raina SS, Karppinen J, Hakala M, Palm T, Kroger H, Kaitila I, et al. Identification of a novel common genetic risk factor for lumbar disk disease. Jama. 2001;285(14):1843-9.

18. Bagheri $\mathrm{MH}$, Honarpisheh AP, Yavarian M, Alavi Z, Siegelman J, Valtchinov VI. MRI Phenotyping of COL9A2/Trp2 and COL9A3/Trp3 Alleles in Lumbar Disc Disease: A Case-control Study in South-Western Iranian Population Reveals a Significant Trp3-Disease Association in Males. Spine. 2016;41(21):1661-67. 
19. Solovieva S, Lohiniva J, Leino-Arjas P, Raininko R, Luoma K, Ala-Kokko L, Riihimaki H. COL9A3 gene polymorphism and obesity in intervertebral disc degeneration of the lumbar spine: evidence of gene-environment interaction. Spine. 2002;27(23):2691-6.

20. Pihlajamaa T, Perala M, Vuoristo MM, Nokelainen $M$, Bodo $M$, Schulthess T, Vuorio E, Timpl R, Engel J, Ala-Kokko L. Characterization of recombinant human type IX collagen. Association of alpha chains into homotrimeric and heterotrimeric molecules. J Biol Chem. 1999;274(32):22464-8.

21. Eskola PJ, Kjaer P, Daavittila IM, Solovieva S, Okuloff A, Sorensen JS, Wedderkopp N, Ala-Kokko L, Mannikko M, Karppinen Jl. Genetic risk factors of disc degeneration among 12-14-year-old Danish children: a population study. Int J Mol Epidemiol Genet. 2010;1(2):158-65.

22. Rathod TN, Chandanwale AS, Gujrathi S, Patil V, Chavan SA, Shah MN Association between single nucleotide polymorphism in collagen IX and intervertebral disc disease in the Indian population. Indian J Orthop. 2012; 46(4):420-6.

23. Jim JJ, Noponen-Hietala N, Cheung KM, Ott J, Karppinen J, Sahraravand A Luk KD, Yip SP, Sham PC, Song YQ, et al. The TRP2 allele of COL9A2 is an age-dependent risk factor for the development and severity of intervertebral disc degeneration. Spine. 2005;30(24):2735-42.

24. Srivastava K, Srivastava A, Sharma KL, Mittal B. Candidate gene studies in gallbladder cancer: a systematic review and meta-analysis. Mutat Res. 2011; 728(1-2):67-79.

25. Clark MF, Baudouin SV. A systematic review of the quality of genetic association studies in human sepsis. Intensive Care Med. 2006;32(11):1706-12.

26. Vrabel M. Preferred reporting items for systematic reviews and metaanalyses. Oncol Nurs Forum. 2015;42(5):552-4.

27. Kales SN, Linos A, Chatzis C, Sai Y, Halla M, Nasioulas G, Christiani DC. The role of collagen IX tryptophan polymorphisms in symptomatic intervertebral disc disease in southern European patients. Spine. 2004;29(11):1266-70.

28. Matsui Y, Mirza SK, Wu JJ, Carter B, Bellabarba C, Shaffrey Cl, Chapman JR, Eyre DR. The association of lumbar spondylolisthesis with collagen IX tryptophan alleles. J Bone Joint Surg Br Vol. 2004;86(7):1021-6.

29. Zhu Y, Wu JJ, Weis MA, Mirza SK, Eyre DR. Type IX collagen neo-deposition in degenerative discs of surgical patients whether genotyped plus or minus for COL9 risk alleles. Spine. 2011;36(24):2031-8

30. Kelempisioti A, Eskola PJ, Okuloff A, Karjalainen U, Takatalo J, Daavittila I, Niinimaki J, Sequeiros RB, Tervonen O, Solovieva S, et al. Genetic susceptibility of intervertebral disc degeneration among young Finnish adults. BMC Med Genet. 2011;12:153.

31. Higgins JP, Thompson SG. Quantifying heterogeneity in a meta-analysis. Stat Med. 2002;21(11):1539-58.

32. Begg CB, Mazumdar M. Operating characteristics of a rank correlation test for publication bias. Biometrics. 1994;50(4):1088-101.

33. Egger M, Davey Smith G, Schneider M, Minder C. Bias in meta-analysis detected by a simple, graphical test. BMJ (Clin Res Ed). 1997;315(7109):629-34.

34. Martirosyan NL, Patel AA, Carotenuto A, Kalani MY, Belykh E, Walker CT, Preul MC, Theodore N. Genetic alterations in intervertebral disc disease. Front Surg. 2016:3:59.

35. Feng $\mathrm{H}$, Danfelter $\mathrm{M}$, Stromqvist $\mathrm{B}$, Heinegard $\mathrm{D}$. Extracellular matrix in disc degeneration. J Bone Joint Surg Am. 2006;88(Suppl 2):25-9.

36. Kimura T, Nakata K, Tsumaki N, Miyamoto S, Matsui Y, Ebara S, Ochi T. Progressive degeneration of articular cartilage and intervertebral discs. An experimental study in transgenic mice bearing a type IX collagen mutation. Int Orthop. 1996:20(3):177-81.

37. Janeczko L, Janeczko M, Chrzanowski R, Zielinski G. The role of polymorphisms of genes encoding collagen IX and XI in lumbar disc disease. Neurol Neurochir Pol. 2014;48(1):60-2.

\section{Ready to submit your research? Choose BMC and benefit from:}

- fast, convenient online submission

- thorough peer review by experienced researchers in your field

- rapid publication on acceptance

- support for research data, including large and complex data types

- gold Open Access which fosters wider collaboration and increased citations

- maximum visibility for your research: over $100 \mathrm{M}$ website views per year

At $\mathrm{BMC}$, research is always in progress.

Learn more biomedcentral.com/submissions 